\title{
Comparative Study of Widal Test and IgM ELISA in the Diagnosis of Typhoid Fever
}

\author{
Supriya Christopher ${ }^{1}$, Anjana Gopi² ${ }^{2}$ Akshatha Ningaraju ${ }^{3}$ \\ 1,2,3, Department of Microbiology, Kempegowda Institute of Medical Sciences, Bangalore, Karnataka, India.
}

\section{ABSTRACT}

\section{BACKGROUND}

Typhoid fever is an intense multi-system illness characterized by extended fever, and sustained bacteraemia. Typhoid fever is especially predominant in developing countries, where the standard of personal hygiene is poor with incidence of contaminated food, and water. It is endemic in India. Diagnosis of typhoid fever at an early stage is very critical. Salmonella Typhi isolation from bone marrow is the gold standard method for confirming a case of typhoid fever, but requires well trained personnel and equipment. Hence, there is a need for alternate methods of diagnosis. We wanted to compare the effectiveness and reliability of the Widal test and ELISA for the diagnosis of typhoid fever.

\section{METHODS}

A total of 57 blood samples was collected from patients from Kempe Gowda Institute of Medical Sciences, during period of August 2017 and September 2017. Samples were subjected to Widal and IgM ELISA. This is a prospective observational study.

\section{RESULTS}

Out of the 57 samples tested, 7 tested positive for Widal at a titre of 1:160 and above, and 7 tested positive for the IgM ELISA. 50 were negative by both Widal and ELISA, 4 were positive by both Widal and ELISA, 3 were positive by Widal but negative by ELISA and 3 were negative by Widal but positive by ELISA. Additionally, 2 samples that were negative by Widal (Titre $=1: 80$ ) with advice to repeat the test after 1 week were positive by ELISA.

\section{CONCLUSIONS}

There is a need for an alternative method for diagnosing Typhoid fever, Widal now being the standard test, is less reliable when compared to blood culture, which is practically not feasible in all areas. IgM ELISA can serve as a rapid test and can detect the illness in the first week of illness and results can be obtained within few hours. This gains importance in early diagnosis and hence better management of the disease.
Corresponding Author: Dr. Akshatha Ningaraju, No. 237, 6th main, 2nd cross, D cross, $3^{\text {rd }}$ Block, 3rd Stage, Basaveshwaranagar, Bangalore 560079, Karnataka, India.

E-mail: akshathakshuz@gmail.com

DOI: $10.14260 /$ jemds/2020/822

How to Cite This Article:

Christopher S, Gopi A, Ningaraju A. Comparative study of widal test and IgM ELISA in the diagnosis of typhoid fever. $J$ Evolution Med Dent Sci 2020;9(49):37433747, DOI: $10.14260 /$ jemds/2020/822

Submission 11-08-2020,

Peer Review 23-10-2020,

Acceptance 29-10-2020,

Published 07-12-2020.

Copyright (C) 2020 Supriya Christopher et al. This is an open access article distributed under Creative Commons Attribution License [Attribution 4.0 International (CC $B Y 4.0)]$

\section{KEY WORDS}

Widal, ELISA IgM, Salmonella Typhi, Typhoid Fever 


\section{BACKGROUND}

Typhoid fever, resulting from Salmonella enterica subspecies enterica serovar Typhi, is one of the most prevalent health problems worldwide with an estimated 16.6 million cases that result in 600,000 deaths each year. ${ }^{1}$ Typhoid fever is a potentially fatal multi-system illness with classic presentation of extended fever, sustained bacteraemia without endothelial or endocardia involvement, and bacterial multiplication within the mononuclear phagocytic cells of the liver, spleen, lymph nodes and Peyer's patches. ${ }^{2}$

The ailment is unique to human, and infection occurs in all age groups but with a higher incidence and more variable clinical presentation in youngsters. But, its real impact is difficult to estimate because the clinical picture is confusing with other febrile infections. It is characterized by malaise, fever, abdominal discomfort, transient rash (rose spots), splenomegaly, hepatomegaly, bradycardia and leucopoenia. The major complications are intestinal haemorrhage and perforation. $^{2} 2-40 \%$ of patients show neurological manifestations which include meningitis, Guillain-Barré syndrome, neuritis and neuropsychiatric symptoms, with picking at bedclothes or imaginary objects. Disseminated intravascular coagulation, hemophagocytic syndrome, pancreatitis, myocarditis, orchitis, hepatitis, glomerulonephritis, pyelonephritis and haemolytic uremic syndrome, sever pneumonia, arthritis, osteomyelitis, and parotitis are rare complications. ${ }^{3}$

Typhoid fever is especially prevalent in developing countries, where there is negative standard of personal hygiene, and prevalence of contaminated food, water is more. ${ }^{4}$ It is endemic in India. Risk factors include contaminated water or ice, flooding, food and drinks purchased from street vendors, raw fruits and vegetables grown in fields fertilized with sewage, ill contacts in household, lack of personal hygiene and evidence of prior Helicobacter pylori infection, likely related to chronic reduced gastric acidity.

Accurate diagnosis of typhoid fever at an early stage is essential not only for aetiological diagnosis, but also to identify individuals who may serve as a potential carrier, who may be liable for acute typhoid fever outbreaks ${ }^{2}$. The clinical diagnosis of typhoid fever is difficult, as the presenting symptoms are often variable and just like the ones observed with other febrile illnesses. The definitive diagnosis of typhoid fever requires the isolation of Salmonella Typhi from the patient concerned. 5

Isolation of Salmonella Typhi from bone marrow is the current gold standard method for confirming a case of typhoid fever. However, this requires equipment, supplies and trained laboratory personnel seldom found in primary health - care facilities in the developing world.6,7,8 The other methods of diagnosis are blood and faeces culture, which are not always available and takes 2 - 3 days. 9,10

Diagnosis may be delayed or overlooked and patients without typhoid fever may receive unnecessary and inappropriate antimicrobial treatment.9,10 Thus, in developing countries, serological diagnosis has gained importance for diagnosis of typhoid fever.

The most popular serological test used for the detection of typhoid fever is the Widal test which is used to measure the antibodies against the $\mathrm{H}$ and $\mathrm{O}$ antigens of typhoid bacilli. However, numerous studies have produced facts that have serious doubts on the values of the Widal test in the diagnosis of typhoid fever. ${ }^{11}$

Hence, there is a need for alternate methods of diagnosis. ${ }^{12}$ In recent years, alternative diagnostic tests involving molecular-based assays have been developed, which are rapid, sensitive, specific and inexpensive. The Enzyme-Linked Immunosorbent Assay (ELISA) is a kind of qualitative enzyme immunoassay and its principle is based on the detection of early rising IgM antibodies to the typhoid specific antigen. It is useful in the diagnosis of infection in the initial weeks with a single serum sample. ${ }^{13}$

The present study was conducted to compare the effectiveness and reliability of the Widal test and ELISA for diagnosis of typhoid fever.

\section{METHODS}

This study was conducted as a type of prospective observational study to compare the potency and reliability of Widal test and IgM ELISA for diagnosis of typhoid fever. It was carried out at KIMS (Kempegowda Institute of Medical Sciences) Hospital and Research Centre, Bangalore between August 2017 and September 2017. Institutional ethical clearance was obtained prior to the start of the study. 57 attending patients clinically suspected of typhoid fever were included.

\section{Inclusion Criteria ${ }^{3}$}

Patients more than 18 years of age, clinically suspected of having typhoid fever and showing the following clinical manifestations -

1. Fever $38.5^{\circ} \mathrm{C}-40.5^{\circ} \mathrm{C}$.

2. Headache, relative bradycardia, chills, vomiting, abdominal pain, coated tongue, splenomegaly.

\section{Exclusion Criteria}

Patients with malaria, dengue, respiratory tract infections, urinary tract infections were excluded from the study by looking into the history, and if needed tests were done.

Only the blood samples of clinically suspected cases of typhoid fever that were sent to the microbiology lab for the purpose of Widal test (SPAN Diagnostics, ARKRAY Healthcare Pvt. Ltd.) were utilized for the study. MedCalc Version 19.4.1 was used for statistical analysis.

\section{RESULTS}

A total of 57 serum samples were utilised in the study. Both the Widal test and IgM ELISA were performed on the samples and the results were analysed.

Agglutination titre values less than 1: 80 were considered negative and agglutination titre values for both $\mathrm{O}$ and $\mathrm{H}$ greater than 1: 80 was considered a positive test. In case the titre value was equal to $1: 80$, a repeat test was advised after 1 week. Out of the 57 samples, a total of 8 and 1 sample had 
significant 0 agglutination titre values $(1: 160$ and $1: 320$ respectively), 7 samples had 0 agglutination titre values equal to $1: 80$ and 41 samples had 0 agglutination titre values less than 1:80. Out of the 57 samples, a total of 6 and 1 sample had significant $H$ agglutination titre values $(1: 160$ and 1:320 respectively), 5 samples had $\mathrm{H}$ agglutination titre values of 1:80 and 45 samples had $\mathrm{H}$ agglutination titre values of less than 1:80. Hence, a total of 7 samples had both significant 0 and $\mathrm{H}$ agglutination titre values (more than 1:80) and were considered positive.

\begin{tabular}{|ccccc|}
\hline Widal test & \multicolumn{5}{c|}{ Total no. of samples $=\mathbf{5 7}$} \\
\hline Ab titre to S. Typhi $O$ & $<1: 80$ & $1: 80$ & $1: 160$ & $1: 320$ \\
No. of samples & 41 & 7 & 8 & 1 \\
Ab titre to S. Typhi H & $<1: 80$ & $1: 80$ & $1: 160$ & $1: 320$ \\
No. of samples & 45 & 5 & 6 & 1 \\
\hline Table 1. Results of Widal Slide Agglutination Test \\
\hline
\end{tabular}

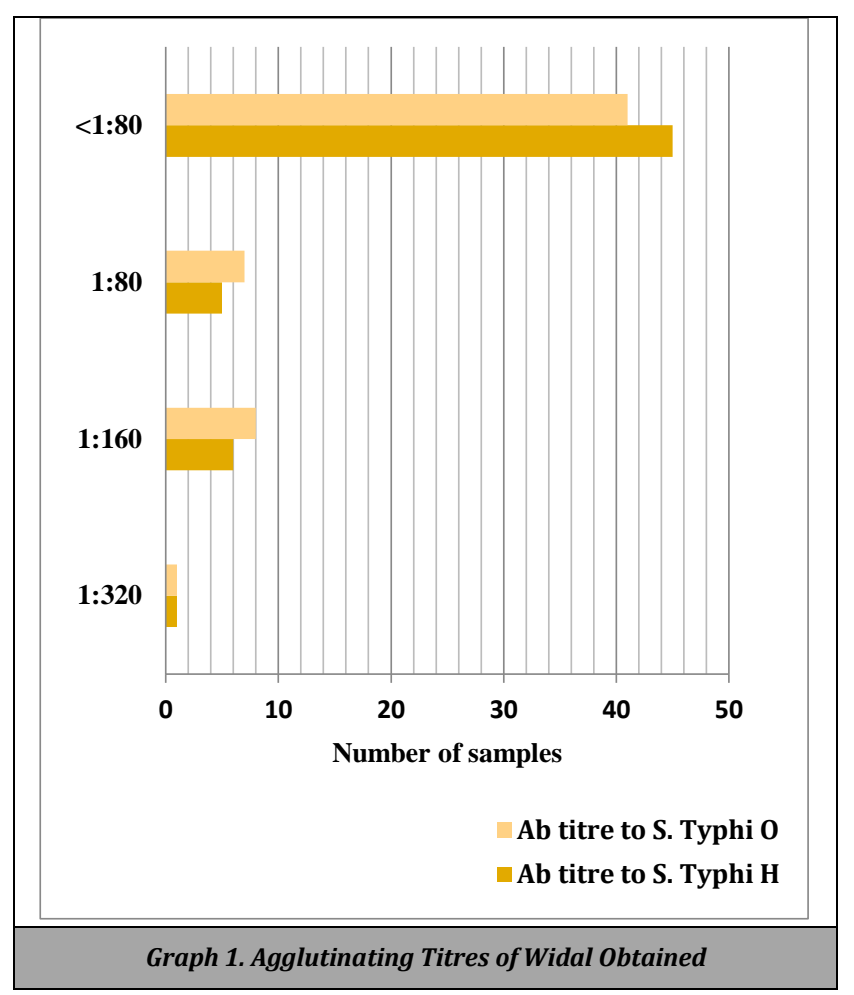

Isolation of Salmonella Typhi from bone marrow is the current gold standard method for confirming a case of typhoid fever.

\begin{tabular}{|cc|}
\hline IgM Elisa & Total No. of Samples $=\mathbf{5 7}$ \\
Positive & 7 \\
Negative & 50 \\
\hline & Table 2. Results of IgM ELISA \\
\hline
\end{tabular}

\section{Interpretation of the test}

Negative $0-0.49$, indicated IgM antibody was not present in the sample.

Positive: Equal or more than 0.5, indicated presence of IgM antibody towards Salmonella Typhi

Out of 57 samples, 50 samples had OD values less than 0.5 and thus, were considered negative while 7 samples had OD values equal or more than 0.5 and thus, were considered positive.

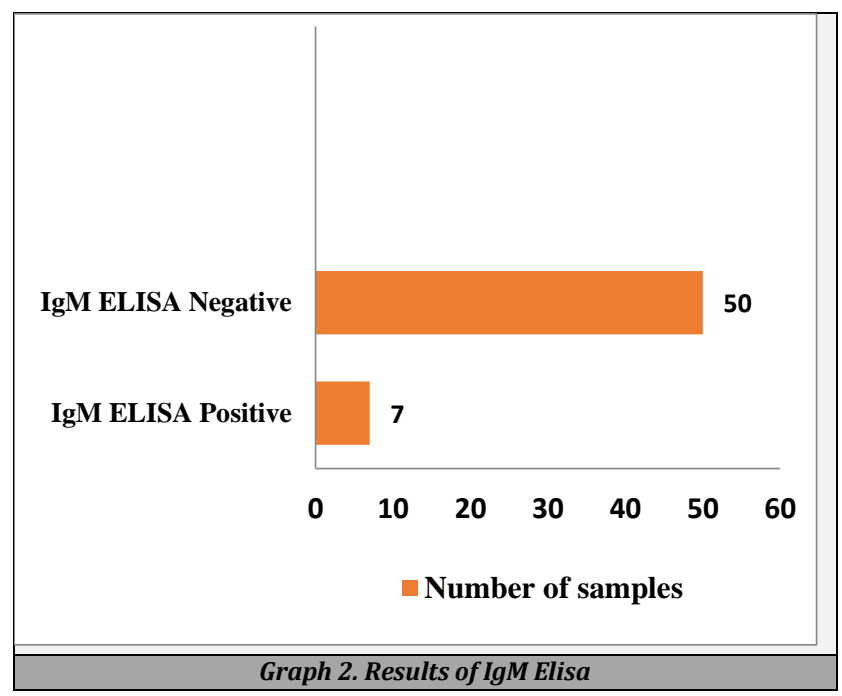

\begin{tabular}{|ccc|}
\hline Widal & Positive & IgM \\
Positive & 4 & Negative \\
Negative & 0 & 3 \\
\hline Table 3. Comparisons of Widal and IgM Elisa \\
\hline
\end{tabular}

\begin{tabular}{|ccccc|}
\hline Sensitivity & Specificity & PPV & NPV & Accuracy \\
100 & 94.38 & 57 & 100 & 94.7 \\
\hline \multicolumn{4}{|c|}{ Table 4. Sensitivity, Specificity, PPV, NPV, Accuracy } \\
\hline
\end{tabular}

\section{Comparison of Widal Test and IgM ELISA \\ (Table 3)}

Out of the 57 samples tested, 7 tested positive for Widal at a titre of 1:160 and above, and 7 tested positive for the IgM ELISA. 50 were negative by both Widal and ELISA, 4 were positive by both Widal and ELISA, 3 were positive by Widal but negative by ELISA and 3 were negative by Widal but positive by ELISA. Additionally, 2 samples that were negative by Widal (Titre $=1: 80$ ) with advice to repeat the test after 1 week were positive by ELISA.

\section{DISCUSSION}

Typhoid fever is one of the most prevalent health problems across the world and the burden is especially seen in developing countries like India. The diagnosis of typhoid fever based on clinical grounds is not very reliable since, they are similar to the symptoms present in other febrile illnesses. ${ }^{2,5}$ Culture of bone marrow aspirate, blood stool and urine has still remained the gold standard for isolation of Salmonella Typhi. The facilities for culture are not readily available or are limited in many areas. ${ }^{14}, 15$

As an alternative to culture method, search for better and improved test still prevails. It is always necessary for speed and accuracy for effectiveness of diagnosis of typhoid fever. ${ }^{15}$ The most popular serological test used for the detection of typhoid fever is the Widal test which is used to measure the antibodies against the $\mathrm{H}$ and $\mathrm{O}$ antigens of typhoid bacilli. Numerous studies have produced data which has put forth some doubts on the value of the Widal test in the diagnosis of typhoid fever. $11,16,17,18$

Alternate methods of serological detection have been developed, which are rapid, sensitive, specific and affordable. 
The ELISA is a type of qualitative enzyme immunoassay and its principle is based on the detection of early rising IgM antibodies to the typhoid specific antigen. It is useful in the diagnosis of infection in the initial weeks with a single serum sample. ${ }^{13}$

The current study was carried out to compare the diagnostic efficiency of the Widal test with IgM ELISA.

Based on prior studies $2,19,20,21,22,23,24,25$ that concluded that ELISA was a more sensitive and specific test in the diagnosis of typhoid fever as compared to the Widal test, it was decided that the IgM ELISA be used as the standard. The sensitivity and specificity of the Widal test was calculated to be $70 \%$ and $94.34 \%$ respectively.

Both the Widal test and IgM ELISA were performed on the samples and the results were analysed.

According to the results of the study, 7 out of the 57 tested samples were positive for both the Widal test and IgM ELISA. However, all the samples which gave a positive Widal reaction were not the same as the samples which gave a positive ELISA result (refer to Table 3).

3 samples that were found to be positive by the Widal test were found to be negative by ELISA. There may be many reasons that can result in a false positive Widal test. These include-vaccination with Salmonella antigens, non-typhoidal Salmonella can cause cross-reactions, preparation of commercial antigen may be of poor standard and variable, if having other infections caused by dengue, malaria or other Enterobacteriaceae. ${ }^{13,10}$

Additionally, 3 samples that were negative by the Widal test were found to be positive by ELISA. This finding is in agreement with Zorgani and Ziglam, who concluded that a negative Widal test does not rule out typhoid fever. ${ }^{26}$ Causes for a false negative Widal reaction may be-the carrier state, an inadequate inoculum of bacterial antigen in the host to induce antibody production, technical difficulty or errors in the performance of the test, previous antibiotic treatment, variability in the preparation of commercial antigens..$^{13}$

Olopenia and King also suggested that the results of the Widal test should be reported in terms of their agglutination titres, and not merely as positive or negative. ${ }^{13}$ Our study supports this statement with reference to the 7 serum samples that had agglutination titres of 1:80 and were reported negative, but with the advice to repeat the test after 1 week (refer to Table 1). Upon performing the ELISA test on these serum samples, 2 out of 7 samples (28.57\%) were found to be positive. This indicates the usefulness of ELISA in diagnosing infection within the initial few days when the agglutination titres weren't high enough for the Widal test to detect. This gains importance, since the right treatment can be started much earlier, wrong treatment may be avoided and also complications can be prevented.

It was also observed that in both these samples, the 0 agglutination titre was raised more than the $\mathrm{H}$ agglutination titre, which may indicate that the former may have slightly more diagnostic value than the latter. This is in agreement with the study carried out by Pang and Puthucheary. ${ }^{11}$

The study has a number of limitations. It was carried out on a small scale where only a limited number of samples were used. Also, neither the bone marrow culture, which is considered to be the gold standard for diagnosis of typhoid fever, $6,7,27$ nor a blood or faeces culture was used as the standard. Instead, it was based on previous studies that support the use of IgM ELISA as a more sensitive and specific test. This may not reflect the true values and hence, requires a bone marrow culture for accurate results. ${ }^{27}$

\section{CONCLUSIONS}

There is a need for alternative method for diagnosis of Typhoid fever. Though Widal is used as a standard test for the serodiagnosis, it is less reliable. Culture being the most reliable, is not practically feasible in many areas since it requires lab equipment, expertise, and is time consuming Thus, in the absence of culture method, IgM ELISA can serve as a rapid and reliable alternative for the diagnosis of typhoid fever. It is faster, cost effective and is less tedious, especially when done on a large scale It can detect infection within the first week of illness, and results are obtained within a few hours. Thus, it gains importance in the early diagnosis and hence-better management of the disease.

Data sharing statement provided by the authors is available with the full text of this article at jemds.com.

Financial or other competing interests: None.

Disclosure forms provided by the authors are available with the full text of this article at jemds.com.

\section{REFERENCES}

[1] Crump JA, Luby SP, Mintz ED. The global burden of typhoid fever. Bull World Health Organ 2004;82(5):34653.

[2] Saleh MAD. Comparison of widal agglutination test with elisa typhi test for serological diagnosis of typhoid fever in some Iraqi patients in Diyala governorate. IJAR 2013;1(5):59-64.

[3] Fauci AS, Brawnwald E, Kasper DL, et al. Salmonellosis. Part - 7. In: Harrison's Principle of Internal Medicine. 17th edn. US: McGraw-Hill Companies 2008.

[4] Khan KH, Ganjewala D, Rao BKV. Recent advancement in typhoid research - a review. Advanced Biotech 2008.

[5] Alam ABMS, Rupam FA, Chaiti F. Utility of a single widal test in the diagnosis of typhoid fever. Bangladesh J Child Health 2011;35(2):53-8.

[6] Wain J, Hosoglu S. The laboratory diagnosis of enteric fever. J Infect Dev Ctries 2008;2(6):421-5.

[7] Archibald LK, Reller LB. Clinical microbiology in developing countries. Emerg Infect Dis 2001;7(2):302-5.

[8] Ley B, Thriemer K, Ame SM, et al. Assessment and comparative analysis of a rapid diagnostic test (Tubex $\left.{ }^{\circledR}\right)$ for the diagnosis of typhoid fever among hospitalized children in rural Tanzania. BMC Infect Dis 2011;11:147.

[9] Keddy KH, Sooka A, Letsoalo ME, et al. Sensitivity and specificity of typhoid fever rapid antibody tests for laboratory diagnosis at two Sub-Saharan African sites. Bull World Health Organ 2011;89(9):640-7.

[10] Lalremruata R, Chadha S, Bhalla P. Retrospective audit of the widal test for diagnosis of typhoid fever in pediatric patients in an endemic region. J Clin Diagn Res 2014;8(5):DC22-DC5.

[11] Pang T, Puthucheary SD. Significance and value of the widal test in the diagnosis of typhoid fever in an endemic area. J Clin Pathol 1983;36(4):471-5. 
[12] Agbenu E, D’Almeida H, Dagnra Y, et al. Widal test case study in Togo: proposition for a rational use. J Infect Dis Immunity 2011;3(13):222-5.

[13] Anagha K, Deepika B, Shahriar R, et al. The easy and early diagnosis of typhoid fever. J Clin Diagn Res 2012;6(2):198-9.

[14] Willke A, Ergonul O, Bayar B. Widal test in diagnosis of typhoid fever in Turkey. Clin Diagn Lab Immunol 2002;9(4):938-41.

[15] Ismail A. New advances in the diagnosis of typhoid and detection of typhoid carriers. Malays J Med Sci 2000;7(2):3-8.

[16] Reynolds DW, Carpenter L, Simon WH. Diagnostic specificity of Widal's reaction for typhoid fever. JAMA 1970;214(12):2192-3.

[17] Hoffman SL, Flanigan TP, Klancke D, et al. The Widal slide agglutination test, a valuable rapid diagnostic test in typhoid fever patients at the infectious diseases hospital in Jakarta. Am J Epidemiol 1986;123(5):869-75.

[18] Olopoenia L, King A. Widal agglutination test -100 years later: still plagued by controversy. Postgrad Med J 2000;76(892):80-4.

[19] Nandakumar KS, Palanivel V, Muthukkaruppan V. Diagnosis of typhoid fever: detection of Salmonella Typhi porins-specific antibodies by inhibition ELISA. Clin Exp Immunol 1993;94(2):317-21.

[20] Handojo I, Dewi R. The diagnostic value of the ELISA-Ty test for the detection of typhoid fever in children.
Southeast Asian J Trop Med Pub Health 2000;31(4):7027.

[21] House D, Wain J, Ho VA, et al. Serology of typhoid fever in an area of endemicity and its relevance to diagnosis. J Clin Microbiol 2001;39(3):1002-7.

[22] Fadeel MA, House BL, Wasfy MM, et al. Evaluation of a newly developed ELISA against widal, TUBEX-TF and typhidot for typhoid fever surveillance. J Infect Dev Ctries 2011;5(3):169-75.

[23] Quiroga T, Goycoolea M, Tagle R, et al. Diagnosis of typhoid fever by two serologic methods. Enzyme-linked immunosorbent assay of antilipopolysaccharide of Salmonella Typhi antibodies and widal test. Diagn Microbiol Infect Dis 1992;15(8):651-6.

[24] Srivastava L, Srivastava VK. Serological diagnosis of typhoid fever by enzyme-linked immunosorbent assay (ELISA). Ann Trop Paediatr 1986;6(3):191-4.

[25] Adhikari A, Rauniyar R, Raut PP, et al. Evaluation of sensitivity and specificity of ELISA against widal test for typhoid diagnosis in endemic population of Kathmandu. BMC Infect Dis 2015;15:523.

[26] Zorgani A, Ziglam H. Typhoid fever: misuse of Widal test in Libya. J Infect Dev Ctries 2014;8(6):680-7.

[27] Wijedoru L, Mallett S, Parry CM. Rapid diagnostic tests for typhoid and paratyphoid (enteric) fever. Cochrane Database of Syst Rev 2017;5(5):CD008892. 